\title{
Willingness to donate eyes among outpatients attending Muhimbili National Hospital
}

FELICITE - MUKAMANA ( $\nabla$ mbfelicite7@gmail.com )

Muhimbili University of Health and Allied Sciences https://orcid.org/0000-0003-1410-4663

\section{Suzan Nstilane Mosenene}

Muhimbili University of Health and Allied Sciences School of Medicine

Anna John Sanyiwa

Muhimbili University of Health and Allied Sciences School of Medicine

\section{Milka Mafwiri}

Muhimbili University of Health and Allied Sciences School of Medicine John Kisimbi

Muhimbili University of Health and Allied Sciences School of Medicine Celina Joseph Mhina

Muhimbili University of Health and Allied Sciences School of Medicine

\section{Research article}

Keywords:

Posted Date: May 15th, 2019

DOI: https://doi.org/10.21203/rs.2.32/v2

License: (c) (i) This work is licensed under a Creative Commons Attribution 4.0 International License. Read Full License 


\section{Abstract}

Background Willingness to donate eyes and other organs in general is still unsatisfactory worldwide, specifically in low income countries including Sub-Saharan Africa where the awareness about eye and other organs donation is still low. Factors like religion may also affect people's decision making in terms of organ donation. Therefore, it is difficult to have enough tissues for transplant and sustainable local eye banks.

\section{Introduction}

Eye donation is an act of high level kindness to humanity and the society which involve the will of a person to consent for removing one's eyes from the body after death (1-3). Donated eyes are used to treat most cases of blindness due to corneal diseases by corneal transplant, but also they are used for research and teaching purposes. Corneal transplant remains the gold standard treatment for corneal blindness and it is the most common transplant performed worldwide with overall success rate of $85 \%$ $(4-6)$.

Eye donation is a key factor for a sustainable corneal transplant services and eye banking. However, willingness to donate eyes as well as other organs is a complex process with socio-cultural barriers $(3,4,7-9)$. The willingness of the family of a deceased donor to honor the will of their relative is the most important factor to make eye donation possible. This influence of the next of kin of the deceased donor make eye and other organs donation to be not only an individual willingness but a familial mater $(10,11)$.

The barriers to eye donation have the consequence that eye donation is still unsatisfactory worldwide and the number of patients in need of corneal transplant is far higher than the number of people willing to donate eyes $(4,8,12)$. According to a global survey done on corneal transplant and eye bank; the ratio demand/supply is $70: 1$ worldwide and only $37.5 \%$ have adequate access to corneal transplant. Data from this survey showed that high number of people who have no access to corneal transplant services found in Africa and many countries of Asia (4).

In developed countries and some Asian countries like India, Malaysia and Singapore there is an increase in awareness on eye donation and the willingness to donate eyes due to influence of education and technology $(2,3,5,13)$. In most African countries, the factors affecting willingness to donate eyes are not well studied and community education about eye donation is rarely done $(2,4)$. Therefore, it is difficult to know the willingness and perception of the community towards eye donation.

\section{Materials And Methods}

This was a Cross-sectional hospital based study with quantitative and qualitative approach. It was conducted in Ophthalmology and ENT outpatient clinics, at Muhimbili National Hospital (MNH), Dar es Salaam/ Tanzania. The study was conducted from July 2017-December 2017). 
All patients 18 years and above were eligible for the study. Patients with mental health problems and communication problems were excluded from the study.

Study participants for quantitative survey were chosen through systematic random sampling technique. A predesigned pretested Kiswahili questionnaire was used. The questionnaire was a forced choice format, but a free space was provided in case the participant had a different view. A face to face interview was conducted for all participants. The level of knowledge of participants was graded according to modified Bloom's cut off points as: High ( $\geq 8$ correct answers $\rightarrow \geq 80 \%$ ), Moderate (5to 7 correct answers $\rightarrow 50 \%-70 \%$ ) and Low (less than 5 correct answers $\rightarrow \leq 50 \%$ ).

For the qualitative part of the study, Participants for qualitative data were selected by purposive sampling technique. Two focus group discussion (FGD) were conducted in Kiswahili at the end of quantitative survey; one for male (8 participants), and another for female (9 participants). Single-gender FGDs were chosen to allow free discussion and expression of perceptions and emotions about organ donation.

During FGD a guiding script with open ended questions was used. It included questions about awareness, willingness and perceptions about eye donation. The discussion did not follow any structured order. However, probing and additional questions were sometimes needed to guide the discussion and clarify unclear concepts. Audio tape was used to capture information emerged from FGD.

Data analysis: Quantitative data were imported in Statistical package for social sciences (SPSS) version.20 for analysis. Frequencies and proportions were selected for each variable of interest. Multinomial logistic regression was done to test association between willingness and other variables. Level of significance was taken at $P$ value of $<0.05$. The tape-recorded discussions from FGDs were replayed then manually transcribed in Microsoft Word file to maintain the original meaning. FGD were translated in English and systematic thematic analysis was done, whereby all themes emerged from FGD were grouped accordingly.

\section{Results}

\section{Quantitative results}

A total of 434 participants were interviewed in this study. Females were $58.0 \%$; Female to Male ratio was 1.4:1. The most frequent age group was between "18-33" years (44.93\%) (Table 1). Among all participants, only $32.5 \%$ were aware about eye donation (Figure 1 ). For participants who were aware about eye donation, more than a half $(59.6 \%)$ had moderate knowledge about eye donation and only $2.1 \%$ had good knowledge about eye donation (Table 2). Among participants who were aware of eye donation, 83.7\% knew that donated eyes are used for corneal transplant (Table 3). The proportion of participants who were willing to donate eyes was $47.9 \%$ (Figure 2). The most frequent reason for willingness (64.25\%) was to help a blind person, while lack of information was the most frequent reason for unwillingness (31.72\%) (Table 4). Multinomial logistic regression showed that willingness to donate eyes was associated with awareness $P<0.0001)$, religion $(p=0.010)$ and sex $(p=0.049)$ (Table 5). Eightytwo percent (82.3\%) of study participants agreed that eye donation is important (Figure 3 ). The most 
frequent reason associated with positive perception was that "eye donation can reduce the burden of blindness" (83.5\%), while negative perception was mainly associated with the fact that "eye donation can cause organ trafficking" (53.5\%) (Table 6). Nearly half (45.2\%) of the participants who had positive perception believe that to become an eye donor is a personal decision. (Figure 4)

\section{Qualitative results}

Different ideas about eye donation were revealed after analysis focus group discussion (FGD)and they were grouped in eight main themes:

\section{Theme 1. Helping others}

Some participants perceived eye donation is a good thing to be done: Something to help a sick person, it cannot be a problem. As the blood, even though with the blood you are still alive but it is the same, to help a person who is alive. (FGD, female)

Eye donation is good if it does not affect the donor's appearance: For me if you tell me to donate my eyes after my death to help another person, there is no problem as long as my look will not be affected. Because if my children see me at last they may run away saying this is not our mum. If I will look normal, no problem. (FGD, female).

\section{Theme 2. Religion}

Participants who were not willing to donate raised the issue of religious beliefs. The concern of after life was revealed, there is a possibility that people will be resurrected without their eyes if they donate them: We were told that there is resurrection after death, one will ask, when the end comes and being resurrected he/she will not have an eye (FGD, Male).

Others fear to be answerable before God, but also think that transplant seems as if people want to challenge God in creation: Myself I cannot accept to donate. First of all, in my religious beliefs, God created everybody with his/her organs. As you remove my organ and put it in another body, it is as if you are teaching God to create. Then if God protected me with all my organs up to my death, if you remove some of them and I am going to Him, I think it is not right! (FGD, Christian)

\section{Theme 3: Fear}

Personal fear emerged as a barrier to donate: For me, I don't want to comment anything because I see huuum! to be removed an eye is another story. I take it in another perspective. I see aaaa! I cannot donate my eyes even if I am dead.... I don't know I am scared. (FGD, female)

Fear of the community harm to donors by people who have relatives in need of organ transplant was raised: It is suspicious. Assume I know you as an eye donor and you have good vision, I can plan and kill you so that your eyes are given to my relative who is in need of them. (FGD, male). 
A kind of jealousy was expressed, where family members of the donor may feel bad seeing the recipient of their relative's eyes: This issue of allowing someone else to use the organ of your close relative is difficult. Imagine your father is dead, his eyes are used by someone else and he/she is enjoying life, seeing him/her is really painful." (FGD, male).

\section{Theme 4. Death and body respect}

Traditional beliefs associated with death were raised as far as eye donation is concerned. Eye donation services are thought to be disrespectful of the deceased: In our African community and Tanzania specifically, it is important to respect the body of a dead person. If you start saying the need of removing eyes, it can bring problems. (FGD, female).

Lack of knowledge make some people to think that eye donation services are illegal: I think that to receive an organ from a dead person is against human right, why take an organ from a dead person and give it to a living one? A person should be buried complete. (FGD, male).

Emotions and fear associated with death were also expressed: To remove eyes while a person is dead!! It is still a big problem. In normal circumstances just like that!! (FGD, female)

Natural fear of a dead person may lead people to refuse donated eyes: I don't think that people will accept to receive eyes from a dead person. I don't think so. (FGD, female).

It is not good to ask for consent for organ donation while a person is dying, that can increase stress for relative and hinder willingness to donate eyes: Talk to healthy people. go in schools and somewhere else, let people sign while they do not show any sign of disease or death, like in blood donation. But if you wait for somebody to be sick and you start telling people "we need eyes of your relative. eeh! (FGD, female).

It may be difficult to talk about eye donation with somebody who is not stable emotionally: To discuss eye donation with relative is not easy. First of all, you have to know that they have lost their beloved one! (FGD, female).

\section{Theme 5. Organ trafficking}

Participants raised the issue of advertisement as people may be worried about it: It should not be a business to advertise because people will think of organ trafficking or witchcraft. Yeah, do not advertise people's organs. Give education but not advertisements. (FGD, female).

Warning about buying organs was given in these words: If you will be buying organs, it will cause murders in the community. But if you put a clear process to donate, nothing bad will happen. (FGD, female).

\section{Theme 6: Community education}


Community education was the main condition under which eye donation can be accepted: First you provide education to people regarding eye donation, when they are educated, they will just accept, what matters is education (FGD, male). Education about eye donation is important to avoid negative perception: If the community is educated, then people will be able to differentiate between legal and illegal things. ( $F G D$, female)

People who benefited from donated eyes are good witness to educate the community: I was just saying that, people who have been benefited from this service should come out as vivid examples so that other people or the whole community would see the importance of this service (FGD, male.

\section{Theme 7. Benefit of eye donation services}

Health benefit: Eye donation in the country will contribute in lessening the burden of blindness: it will reduce the number of blind people, people will have their sight back and continue with their daily activities, because the dead person has no any potential, instead of being buried with the organ, it is better to give to someone who is still alive. (FGD, male).

Eye donation services will help blind people to be productive again: It will increase manpower, I have an example of my uncle, who got education through government, and then he has his leg amputated, he cannot work anymore hence the decrease of manpower, but as for this when this comes, it will increase manpower. (FGD, female)

Economic benefit: It will reduce the cost of corneal transplant: It will reduce the cost of treatment, you know going abroad for treatment, and getting treatment in the country are two different things, it will reduce the cost, for transport, accommodation and food (FGD, female).

Money being send abroad for this services will remain for the benefit of the country: It will help. Our money instead of taking it to foreign countries, it will just remain here for the development of our country. (FGD male).

Professional benefits: Professionals will increase in our country, people will get jobs in that knew field of work: When this service is put in place, our people will benefit, because they will just go and specialise on that issue. Other people will be hired to work in those services. (FGD, female).

Local doctors will gain trust from the population: You know we tend to trust doctors from foreign countries but if the service will be efficient here, we will also trust our own doctors. (FGD, female).

\section{Theme 9. Decision making about being an eye donor.}

To became an eye donor is personal decision, but family members should be informed to avoid any misunderstandings when the donor is gone: For me that one, I see it is my personal decision, but it is mandatory to tell my relatives that I signed a donor card that my eyes will be taken after my death. By informing them, at the time of my death they will not be astonished (FGD, female). Firm decision to be an 
eye donor is necessary to convince family members: That is like sacrifice. If I decide to help someone with my eyes after my death, I will educate them and tell them that it is a sacrifice to give sight to someone because I am no longer alive... so they won't refuse. Telling them before or after I sign, it won't change my decision. (FGD, female).

\section{Discussion}

This study gave a baseline information about willingness and perception about eye donation in Tanzania. About one third of participants were aware of eye donation. The participants have low awareness about eye donation because the services have not yet started in Tanzania. However, these results are comparable with studies done in central Ethiopia and rural India $(8,14)$. Among all participants who were aware of eye donation, majority knew that donated eyes are used for corneal transplant as compared to other uses like research and teaching. This also was reported in previous studies, where corneal transplant seemed to be the most known use of donated eyes $(2,3,12,13)$.

Nearly a half of the participants were willing to donate eyes in this study, while only one third was aware. These results are similar to the study done in central Ethiopia, (8), but contrary to other studies like those done in Nigeria and Asia where the proportion of people willing to donate eyes seemed to be low compared to awareness $(5,9,12,13,15,16)$. This disparity might be due to differences in socio-cultural beliefs.

Willingness to donate eyes is influenced by awareness, sex and religion. Respondents who were aware of eye donation were more willing to donate their eyes compared to others. This reality was shared by majority of studies done in various areas like in central Ethiopia, Singapore and north Ethiopia(8) Males were more willing than females and Christian were more willing than Muslims. The explanation of this fact may not be straight forward, but it may be due to differences in access to information and religious teachings.

The most common reason associated with willingness to donate eyes was "to help a blind person." Compassion and care to others is a natural character shared by humanity in different populations and culture. Participants explained that it is good to help a blind person with their eyes after death. This was also reported in studies done in central Ethiopia (8), Nigeria (16), Denmark (17), USA(18) and Asian countries $(5,12,17)$.

The need for more information about eye donation was the most frequent reason for unwillingness to donate eyes in the present study. It is obvious that people need information about eye donation, because eye donation services have not yet started in Tanzania. Participants who were aware about eye donation got the information from Radio and Television, listened or watched what is done in other countries. However, a big proportion of the population never heard about eye donation.

Lack of information affects the community perception and results in low willingness to donate eyes. Participants of this study in both male and female FGD raised that concern, explaining that education is 
important for the community to accept eye donation services. Lack of information about eye donation was the first reason for unwillingness in other previous studies done in Nigeria and India $(12,14,16,19)$.

Religious reasons were also associated with unwillingness to donate eyes in this study. Religious beliefs are intertwined with people's life and have influence on their decision making. Participant in FGD expressed a bond between religion and decision making, especially about the body and organs, and claimed that we are all created by God. Therefore, only God has power on our bodies and God will punish people who donated their organs. Beliefs about new life after death, make some people to think they will have a second life with incomplete organs if they donate some of them. Similar concerns were raised in the studies done in Ethiopia (8), USA(18) and UK (20), but less common in majority of the studies done in Asia $(3,5,8,14)$.

Positive perception toward eye donation was seen in majority of our study participants. They expressed that eye donation services contribute in reduction of blindness, but also will reduce the cost of corneal transplant. Professional benefits like jobs and learning opportunities for medical professionals are also expected from Eye donation services.

Majority of participants who had negative perception were more worried about organ trafficking". During FGD, participants gave a kind of warning to hospitals not to buy or to advertise organ donation because it can cause murders in the community. It is not ethical to advertise and to buy human organs. However, people are somehow suspicious because they do not have clear information about it. Similar issues reported in Delta state/Nigeria, South Wales/Australia as well as in the USA $(16,18,20,21)$.

Negative perception was again associated with the fact that eye donation is a kind of "torture to the donor's". Participants in the current study during FGD seemed to be much concerned about the issue. Some of them were claiming that the dead person should be buried complete! To remove some organs from the body, would be disrespecting the deceased and violating human rights. The concern goes about cultural rituals associated with dead body but again stress to family members think that their relative's body will be incomplete, while others were wondering on how an organ of a dead person can live in the body of a living person. The same worries were raised in studies done in the UK, New South Wales/Australia and in Singapore $(5,7,21)$.

Nearly a half of participants with positive perception think that consent for eye donation is a personal decision. However, family members should be informed in order to avoid any misunderstanding after donor's death, in case of consent for organ harvest from the body of the deceased. Therefore, to carry an organ donor card is a personal decision but organ donation as a whole is a family matter.

The rest of the participants in quantitative part of this study expressed dependence on their family members before deciding to be an eye donor. The majority mentioned parents and spouses, few mentioned head of the family and religious leaders. It is important to maintain family unity after death of a member of the family. Therefore, some people who do not have objection to organ donation end up not donating because some of their family members do not like organ donation and transplant. In Tanzania, 
as the service has not yet started, family reaction about eye donation is not yet experienced and cannot be discussed now. However, it has to be reviewed in the future when eye donation services are established in the country.

\section{Conclusion}

The present study showed that majority of the participants were not aware of eye donation. However, willingness to donate eyes was seen in nearly a half of the study participants. Willingness to donate eyes was associated with awareness about eye donation, religion and sex. Most of the participants think that eye donation services are important for the population and to become an eye donor is a personal decision. Negative perception about eye donation was associated with lack of information, cultural beliefs, religious beliefs as well as personal fear.

\section{Declarations}

Acknowledgement: We acknowledge Fred Hollows foundation for financial support and our participants for their participation

Ethical approval: Ethical clearance was issued by Muhimbili University of Health and Allied Sciences (MUHAS) ethical committee, Muhimbili National Hospital(MNH) research department, Ophthalmology and ENT departments. Written consent was given by each participant

Authors contribution: FM was the principal investigator; she ran the overall research project from proposal development to manuscript preparation. SM and JK provided comment and gave input on the study design and analysis for quantitative part of the study. AJS provided professional consultancy on quantitative part of the study.

Competing interest: The authors have no financial or non-financial interest in any material of this article.

Funding: Fred Hollows foundation provided all financial support spent on this work.

Availability of Data and material: A copy of data collection tool used in the current study is provided in this manuscript. However, the data sets generated and analyzed are available from the corresponding author on reasonable request.

Consent for publication: Consent for publication is not applicable because this study did not consist of individuals' data.

Authors' information: 1Department of ophthalmology, Muhimbili University of Health and Allied Sciences, Dar es salaam /Tanzania.

\section{References}


1. Murugesan Vanathi, Radhika Tandon, Anita Panda SV\& SK. Challenges of eye banking in a developing world. Expert Rev Ophthalmol. 2007;2(6):923-30.

2. Tiwari R, Diwakar A, Marskole P, Bhargo L, Anwar D. A study to assess awareness on eye donation and willingness to pledge eyes for donation in adult population in Gwalior district (M.P.), India. Int J Res Med Sci. 2014;2(2):662.

3. Srivastava S, Kulthe BS G. H. Awareness of Eye Donation and Willingness to Donate Eyes in Population Attending Outdoor Patients Department of Ophthalmology at Sknmc, Pune (Maharashtra ). Indian J Appl Res. 2015;5(1):451-3.

4. Gain P, Jullienne R, He Z, Aldossary M. Global Survey of Corneal Transplantation and Eye Banking. JAMA Ophthalmol. 2016;134(2):167-73.

5. Yew Y-W, Saw S-M, Pan JC-H, Shen H-M, Lwin M, Yew M-S, et al. Knowledge and beliefs on corneal donation in Singapore adults. Br J Ophthalmol. 2005;89(7):835-40.

6. American academy of ophthalmologist. External Disease and Cornea. In: Association T eye $M$, editor. Basic and clinical science courses. section 8. Life long education for the ohthalmologist; 2012. p. 471.

7. Randhawa $G$. An exploratory study examining the influence of religion on attitudes towards organ donation among the Asian population in Luton, UK. Nephrol Dial Transplant. 1998;13(8):1949-54.

8. GW G, Tilahun $Y$. Willingness to donate eyes and associated factors among adults in a rural community in Central Ethiopia. J Ophthalmol East Cent South Africa . 2013;20-4.

9. JM Waziri-Erameh, AO Ernest OE. Knowledge And Attitude Of Nigerian Ophthalmologists Towards Cornea Donation And Corneal Graft. J Med Biomed Res. 2007;5((1\&2)):26-34.

10. Hermel M, Monhof K, Steinfeld A, Salla S, Hamsley N, Walter P, et al. The Role of Specifically Tailored Communication Training Among Factors Influencing Consent for Cornea Donation Requested Via Telephone. Transplantation. 2015;99(10):2223-9.

11. Gillon S, Hurlow A, Rayment C, Zacharias H, Lennard R. Obstacles to corneal donation amongst hospice inpatients: a questionnaire survey of multi-disciplinary team member's attitudes, knowledge, practice and experience. Palliat Med. 2012;26(7):939-46.

12. Yajaman SR, VS, S P. Awareness and Willingness of Eye Donation Among Attendants of Patients in Rural Karnataka. J Evid Based Med HIthcare. 2015;2(43):7633-7.

13. Bhandary S, Khanna R, Rao K, Rao L, Lingam K, Binu V. Eye donation - Awareness and willingness among attendants of patients at various clinics in Melaka, Malaysia. Indian J Ophthalmol. 2011;59(1):41. 
14. Krishnaiah S, Kovai V, Nutheti R, Shamanna BR, Thomas R, Rao GN. Awareness of eye donation in the rural population of India. Indian J Ophthalmol. 2004;52(1):73-8.

15. Puri S, Gupta N, Bansal S, Ram J, Arya S, Sood S. Gender - A barrier for Willingness to Eye Donation? Int J Preven Curat Comm Med. 2016;2(1):31-5.

16. Abadom EG, Otene Cl, Enivwenae AO. Knowlegde and willingness to donate eye among medical doctors in delta state. J Dent Med Sci. 2014;13(6):57-63.

17. Nordfalk F, Olejaz M, Jensen AMB, Skovgaard LL, Hoeyer K. From motivation to acceptability: A survey of public attitudes towards organ donation in Denmark. Transplant Res. 2016;5(1):1-8.

18. Morgan SE, Harrison TR, Afifi WA, Long SD, Stephenson MT. In their own words: The reasons why people will (not) sign an organ donor card. Health Commun. 2008;23(1):23-33.

19. Dandona R, Dandona L, John RK, McCarty CA, Rao GN. Awareness of eye donation in an urban population in southern India. Aust N Z J Ophthalmol. 2001;79(2):96-102.

20. Newton JD. How does the general public view posthumous organ donation? A meta-synthesis of the qualitative literature. BMC Public Health. 2011;11(1):791.

21. Lawlor M, Kerridge I, Ankeny R, Dobbins TA, Billson F. Specific unwillingness to donate eyes: The impact of disfigurement, knowledge and procurement on corneal donation. Am J Transpl.

2010;10(3):657-63.

\section{Table 1: Demographic Characteristics Of Participants}




\begin{tabular}{|c|c|c|c|}
\hline \multicolumn{2}{|c|}{ Characteristics } & Frequency & Percent \\
\hline \multirow[t]{4}{*}{ Age group(years) } & 18-33 & 195 & $44.9 \%$ \\
\hline & $34-48$ & 141 & $32.5 \%$ \\
\hline & $49-63$ & 71 & $16.3 \%$ \\
\hline & 64 and above & 27 & $6.3 \%$ \\
\hline \multirow[t]{2}{*}{ Sex } & Male & 182 & $42.0 \%$ \\
\hline & Female & 252 & $58.0 \%$ \\
\hline \multirow[t]{2}{*}{ Religion } & Muslim & 182 & $41.9 \%$ \\
\hline & Christian & 252 & $58.0 \%$ \\
\hline \multirow[t]{4}{*}{ Marital status } & Single & 127 & $29.2 \%$ \\
\hline & Married & 279 & $64.3 \%$ \\
\hline & Widow/widower & 19 & $4.4 \%$ \\
\hline & Divorced & 9 & $2.1 \%$ \\
\hline \multirow[t]{2}{*}{ Residence } & Dar es Salaam & 322 & $74.1 \%$ \\
\hline & Other* & 112 & $25.8 \%$ \\
\hline \multirow[t]{4}{*}{ Level of education } & No formal education & 19 & $4.4 \%$ \\
\hline & Primary & 172 & $39.6 \%$ \\
\hline & Secondary & 126 & $29.0 \%$ \\
\hline & College & 117 & $27.0 \%$ \\
\hline \multirow[t]{5}{*}{ Occupation } & Health workers & 38 & $8.8 \%$ \\
\hline & Medical students & 25 & $5.8 \%$ \\
\hline & Others students & 17 & $3.9 \%$ \\
\hline & Teachers & 28 & $6.5 \%$ \\
\hline & Other occupations & 326 & $75.1 \%$ \\
\hline
\end{tabular}

Note *Other represented regions included: Pwani, Morogoro, Dodoma, Tanga, Lindi, Mtwara Kilimanjaro, Kigoma, Kagera, Mbeya, Ruvuma, Rukwa, Mwanza, Singida, Mara, Iringa, Shinyanga and Zanzibar.

\section{Table 2: Level Of Knowledge About Eye Donation Among Participants Who Were Aware}

\begin{tabular}{lll}
\hline Grades of knowledge $^{*}$ & Frequency & $\%$ \\
\hline High & 3 & $2.1 \%$ \\
Moderate & 84 & $59.6 \%$ \\
Low & 54 & $38.3 \%$ \\
Total & 141 & $100 \%$ \\
\hline
\end{tabular}

Note*The rating was done according to number of answers given by the respondent among 10 questions captured in table 3.

\section{Table 3: Knowledge About Eye Donation Among Participants Who Were Aware}




\begin{tabular}{llc}
\hline Knowledge questions about eye donation & Frequency & Percentage \\
\hline Use of donated eyes & 118 & $83.7 \%$ \\
$\begin{array}{l}\text { 1.Corneal transplant } \\
\text { 2.Teaching and research }\end{array}$ & 35 & $24.8 \%$ \\
$\begin{array}{l}\text { Eligible donors for transplant purposes } \\
\text { 3.People with good health }\end{array}$ & 55 & $39.0 \%$ \\
$\begin{array}{l}\text { Non eligible for transplant purposes } \\
\text { 4.People with infectious diseases }\end{array}$ & 96 & $68.1 \%$ \\
$\begin{array}{l}\text { 5.Children under } 5 \text { years } \\
\text { 6.Old people above } 70 \text { year }\end{array}$ & 68 & $48.2 \%$ \\
$\begin{array}{l}\text { How to become an eye donor? } \\
\text { 7.Writing a will before death }\end{array}$ & 75 & $53.2 \%$ \\
$\begin{array}{l}\text { 8.Consent from close relative after death } \\
\text { When donated eyes are removed from donor's body? }\end{array}$ & 19 \\
$\begin{array}{l}\text { 9.Short time after donor's death } \\
\text { Who is eligible to receive donated eye? }\end{array}$ & 47 & $33.3 \%$ \\
10.Any person in need & 98 & $69.5 \%$ \\
\hline
\end{tabular}

Note*Frequencies and percentages cannot be summed up because of possibility of multiple responses for a single participant.

\section{Table 4: Perceived Reasons Associated With Willingness To Donate Eyes}

\begin{tabular}{llcc}
\hline Reason for willingness/ unwillingness to donate eyes & Frequency & Percentage \\
\hline Reasons for willingness & It is a noble work & 13 & $6.3 \%$ \\
& To help a blind person & 133 & $64.3 \%$ \\
& I don't need eyes after death & 62 & $29.5 \%$ \\
& & & \\
Reasons for unwillingness & It is against my religion & 50 & $22.0 \%$ \\
& It is against my culture belief & 10 & $4.4 \%$ \\
& I am not sure of the use of donated eyes & 56 & $24.7 \%$ \\
& I need more information & 72 & $31.7 \%$ \\
& Other reasons & 38 & $17.2 \%$ \\
\hline
\end{tabular}

Note: Other reasons* given included: eye problems, too old to donate; fear, honour of the body after death, health problems, wants to be buried complete.

\section{Table 5: Factors Affecting Willingness To Donate Eyes}

Note ${ }^{*}$ OR adjusted for all factors in the table. ${ }^{*} \mathrm{Cl}$ : Confidence interval 


\begin{tabular}{|c|c|c|c|c|c|c|c|}
\hline \multicolumn{2}{|l|}{ Factors } & \multirow{2}{*}{$\begin{array}{c}\text { Willing } \\
96(49.2 \%)\end{array}$} & \multirow{2}{*}{$\begin{array}{l}\text { Not willing } \\
99(50.8 \%)\end{array}$} & \multirow{2}{*}{$\frac{O R^{*}}{1.180}$} & $C I^{*}$ & \multirow[t]{2}{*}{$p$-value } & \multirow{5}{*}{$\begin{array}{l}\text { Table 6: } \\
\text { Reasons } \\
\text { Associateo } \\
\text { With } \\
\text { Perception } \\
\text { About Eye } \\
\text { Donation }\end{array}$} \\
\hline \multirow[t]{4}{*}{ Age } & $18-33$ & & & & $0.436-3.190$ & & \\
\hline & $34-48$ & $67(47.5 \%)$ & $74(52.5 \%)$ & 1.158 & \multicolumn{2}{|c|}{$0.443-3.023$} & \\
\hline & $49-63$ & $34(47.9 \%)$ & $37(52.1 \%)$ & 1.070 & \multirow[t]{2}{*}{$0.393-2.912$} & 120.895 & \\
\hline & $\geq 64$ & $11(40.7 \%)$ & $16(59.3 \%)$ & 1.000 & & & \\
\hline \multirow[t]{2}{*}{ Sex } & Male & $101(55.5 \%)$ & $81(44.5 \%$ & 1.773 & \multirow[t]{2}{*}{$1.167-2.694$} & $94 \quad 0.049$ & \\
\hline & Female & $107(42.5 \%)$ & $145(57.5)$ & 1.000 & & & \\
\hline \multirow[t]{3}{*}{ Religion } & Muslim & $70(38.5 \%)$ & 112(61.5) & 0.578 & \multirow[t]{2}{*}{$0.381-0.876$} & $\begin{array}{ll}76 & 0.010\end{array}$ & \\
\hline & Christian & $138(54.8 \%)$ & $114(45.2)$ & 1.000 & & & \\
\hline & None & $3(15.8 \%)$ & $16(84.2 \%)$ & 0.187 & $0.048-0.732$ & $32 \quad 0.327$ & \\
\hline \multirow[t]{3}{*}{ Education } & Primary & $80(46.5 \%)$ & $92(53.5 \%)$ & 0.898 & \multicolumn{2}{|c|}{$0.524-1539$} & \\
\hline & Secondary & $58(46.0 \%)$ & $68(54.0 \%)$ & 0.763 & \multicolumn{2}{|c|}{$0.444-1.310$} & \\
\hline & College & $67(57.3 \%)$ & $50(42.7 \%)$ & 1.000 & & & \\
\hline \multirow[t]{10}{*}{ Awareness } & Aware & $92(65.2 \%)$ & $49(34.8 \%)$ & 2.865 & $1.886-435$ & $<0.0001$ & \\
\hline & Not aware & 116(39.6) & $177(60 . \%)$ & 1.000 & & & \\
\hline & Perception & \multicolumn{4}{|c|}{ Associated reasons } & Frequency* & Percent* \\
\hline & \multirow[t]{3}{*}{ Positive } & \multicolumn{4}{|c|}{ Can reduce the burden of blindness } & 298 & $83.5 \%$ \\
\hline & & \multicolumn{4}{|c|}{$C T^{* *}$ services will be cost effective } & 168 & $47.1 \%$ \\
\hline & & \multicolumn{4}{|c|}{ Can give money to donors and their families } & 6 & $1.7 \%$ \\
\hline & \multirow[t]{4}{*}{ Negative } & \multicolumn{4}{|c|}{ Donor cannot benefit from the service } & 19 & $24.0 \%$ \\
\hline & & \multicolumn{4}{|c|}{ Donor/family may be socially stigmatized } & 15 & $18.7 \%$ \\
\hline & & It is torture to & he dead pers & & & 32 & $41.3 \%$ \\
\hline & & It is a can cau & se organ traff & cking & & 41 & $53.3 \%$ \\
\hline
\end{tabular}

*Note: One respondent could give more than one answer **CT: Corneal Transplant

\section{Figures}




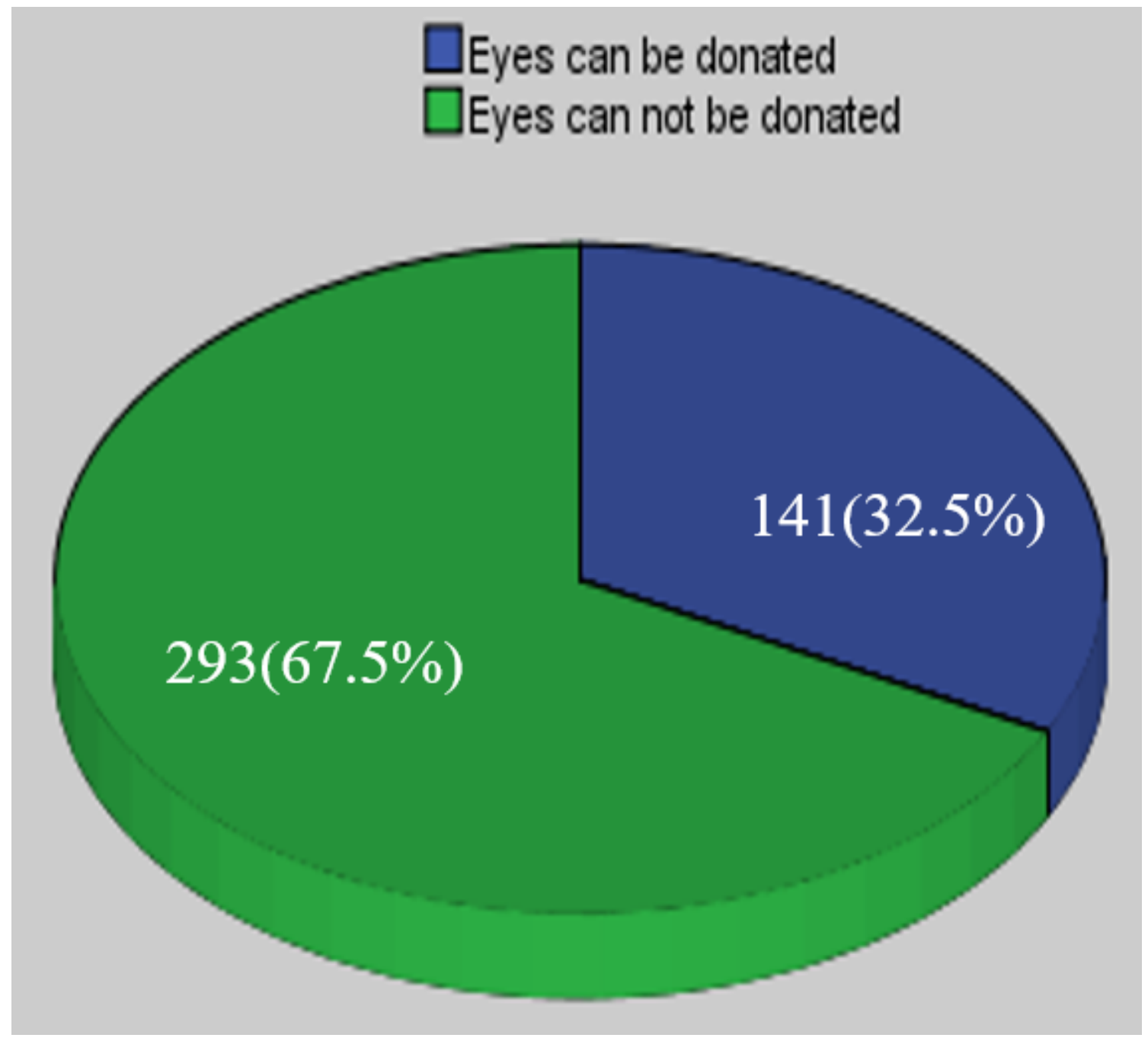

Figure 1

Awareness about eye donation 


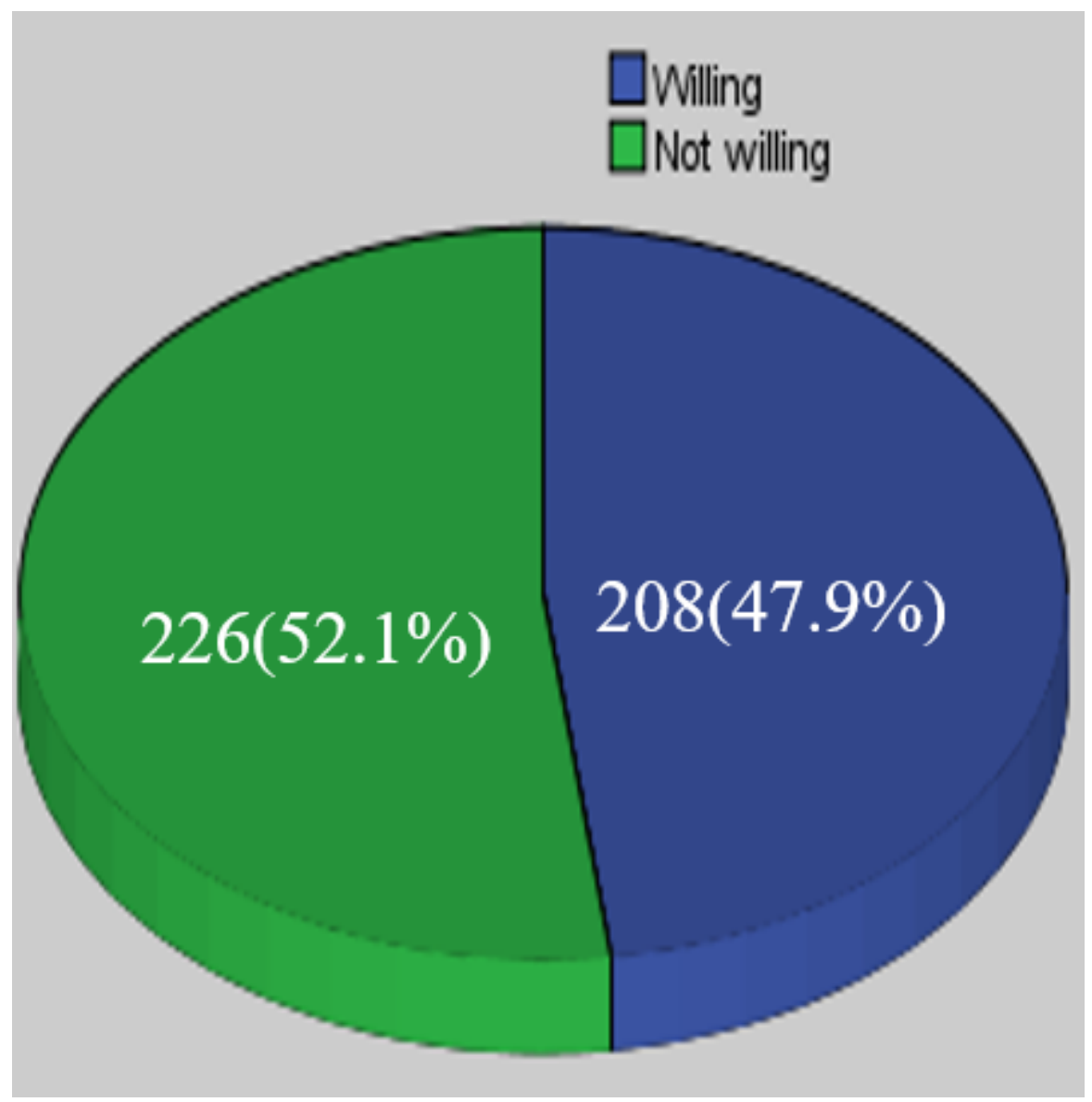

Figure 2

Willingness to donate eyes 


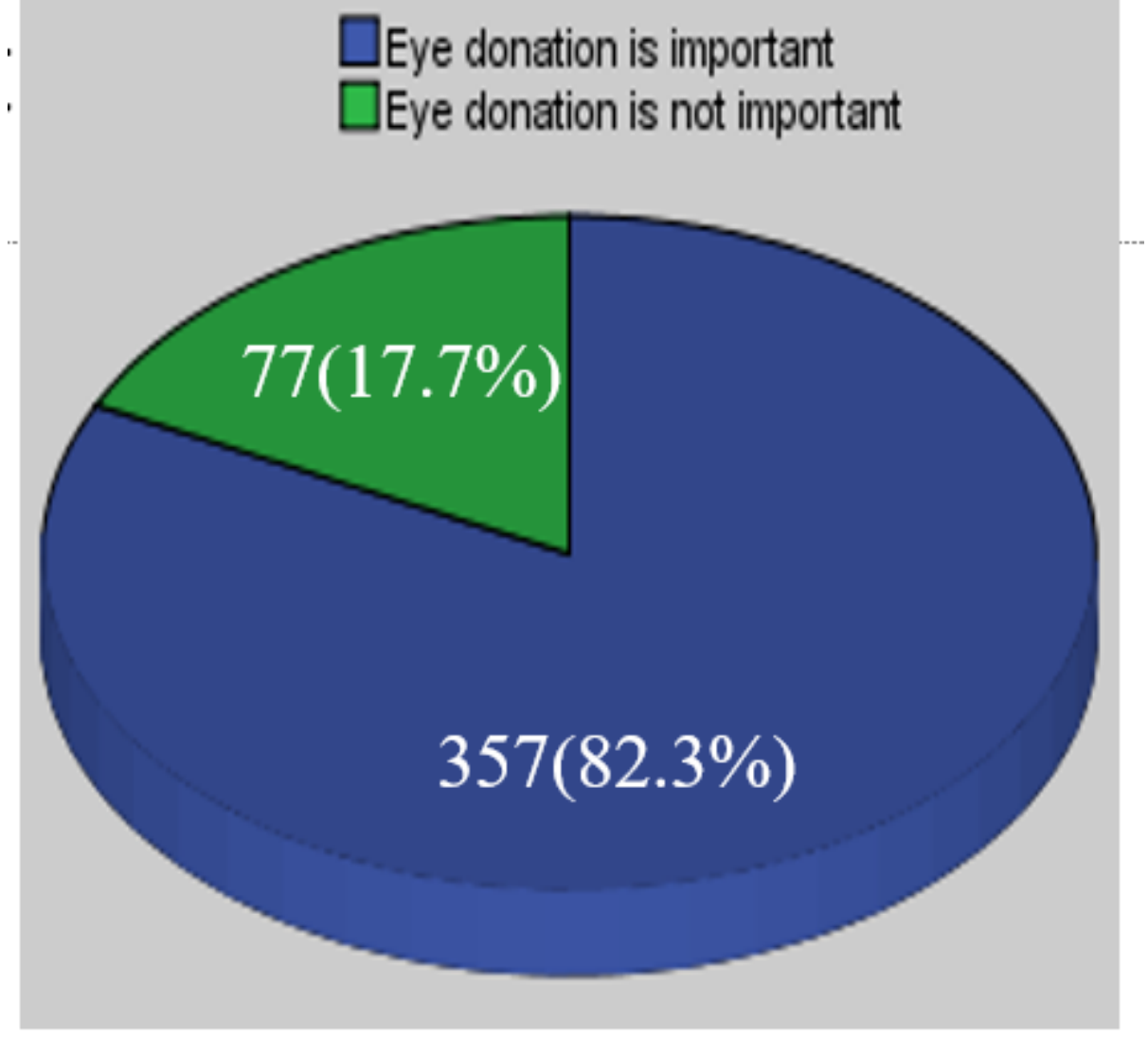

Figure 3

Perception about eye donation 


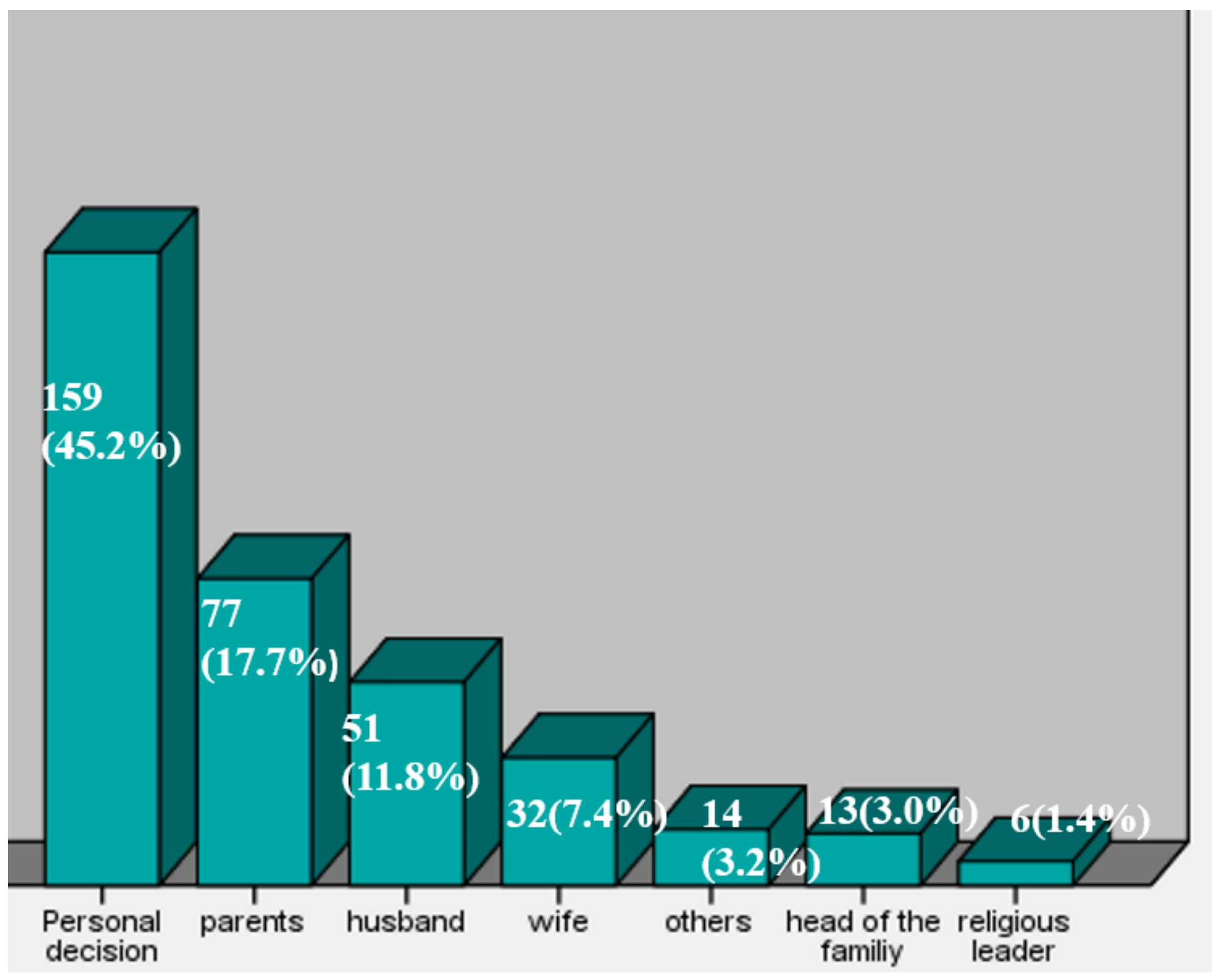

Figure 4

Person to consult before writing a will for eye donation. Others included "children, blood brothers and blood sisters".

Supplementary Files

This is a list of supplementary files associated with this preprint. Click to download.

- supplement1.docx 